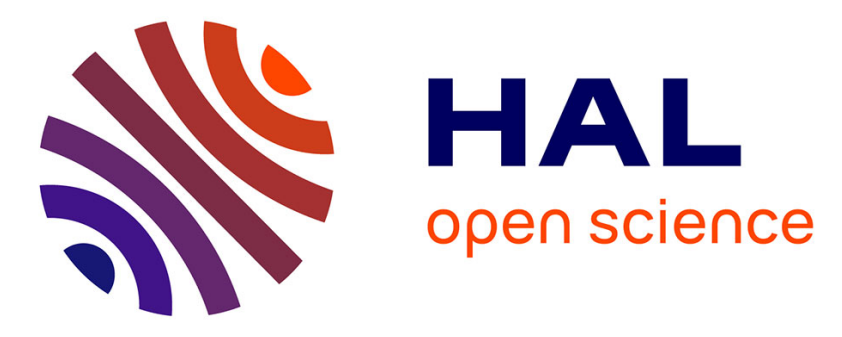

\title{
1D single-shot thermography by Spontaneous Raman Scattering in turbulent, spray or oxyfuel flames
}

Armelle Cessou, Florestan Guichard, Hassan Ajrouche, Amath Lo

\section{To cite this version:}

Armelle Cessou, Florestan Guichard, Hassan Ajrouche, Amath Lo. 1D single-shot thermography by Spontaneous Raman Scattering in turbulent, spray or oxyfuel flames. Laser Applications to Chemical, Security and Environmental Analysis, LACSEA 2018, Jun 2018, Orlando, United States. 10.1364/LACSEA.2018.LTu2C.1 · hal-02393273

\section{HAL Id: hal-02393273 https://hal.science/hal-02393273}

Submitted on 4 Dec 2019

HAL is a multi-disciplinary open access archive for the deposit and dissemination of scientific research documents, whether they are published or not. The documents may come from teaching and research institutions in France or abroad, or from public or private research centers.
L'archive ouverte pluridisciplinaire HAL, est destinée au dépôt et à la diffusion de documents scientifiques de niveau recherche, publiés ou non, émanant des établissements d'enseignement et de recherche français ou étrangers, des laboratoires publics ou privés. 


\title{
1D single-shot thermography by Spontaneous Raman Scattering in turbulent, spray or oxyfuel flames
}

\author{
Armelle Cessou, Florestan Guichard, Hassan Ajrouche, Amath Lo \\ Normandie Univ., UNIROUEN, INSA Rouen, CNRS, CORIA, 76000 Rouen, France \\ Armelle.Cessou@coria.fr
}

\begin{abstract}
Spontaneous Raman scattering noise, limited for thermography in turbulent flames where high spatial and time resolutions are required, is revisited for simultaneous temperature and multispecies concentration single-shot linewise measurements, offering new applications. OCIS codes: (120.0120) General; (120.1740) General
\end{abstract}

\section{Introduction}

High temperature generated by combustion processes has a direct impact on a variety of factors including process efficiency, pollutant levels and product quality. It is therefore of great importance to determine temperature with high accuracy, and to provide reliable data for combustion models, which play an increasingly important role in design and optimization procedures. In turbulent flames, few temperature measurement technics are available and reliable in a large range of operational conditions. Raman/Rayleigh measurements are well known to be a powerful diagnostic tool for instantaneous temperature and major species concentration measurements [1, 2]. Rayleigh scattering is used for temperature measurement, due to its high level of signal-to-noise ratio, associated in an iterative procedure to Spontaneous Raman Scattering (SRS) for major species concentration measurements. By probing of the complete rotational-vibrational energy distribution function with a single laser, SRS is also theoretically a powerful diagnostic for measuring temperature in flames. However its use is restricted by the weakness of its radiation especially in low density media, like flames. Ramanography for time-averaged temperature measurements in flames was proposed by long years ago [3], and if different procedures adapted to the low level signal were proposed [4], their precision and accuracy for single-shot measurements remains limited, especially when the population of the upper vibrational levels is low. If exposure time in laminar flames can be long enough to accumulate sufficient signal with reduced noise, the investigation of turbulent flames imposed very small spatial and time resolutions, which limit the applicability of SRS thermography. Furthermore combustion community has a strong interest in extending instantaneous temperature-concentration measurements, in more complex configuration as spray flames where Rayleigh scattering measurements are biased by the presence of droplets. Only few works mentioned ramanography in spray flames [5,6]: Masri et al [6] determined temperature using the sum of the species number densities of the major species, Grünefeld et al [5] determined average temperature from Stokes/Antistokes ratio in IC engine in the combustion and exhaust strokes when droplets are absent but in hostile environments.

Providing the complete vibrational distribution function and the temperature, SRS has been shown to be an attractive tool for investigation of non-equilibrium reactive flows, like nanosecond pulsed discharges [7-9]. The vibrational distribution function is determined by adjusting theoretical spectra associated to the use of recent spectroscopic data to take into account of the high level of vibrational excitation (up to $v=16$ ), and to determination of the apparatus function at each probe volume simultaneously probed along a line. Taking advantage of the recent technological developments in lasers and detectors, the present paper revisits SRS for instantaneous temperature and multispecies concentration measurements in flames. Sufficient signal-to-noise ratio is obtained for instantaneous temperature measurements with an accuracy of $1 \%$ and a precision smaller than $3 \%$ in burnt gas of air flames. The high accuracy and precision obtained, show that SRS can be envisaged as an alternative way to Rayleigh-SRS method when high stray light occurs: in two-phase media or near walls. Raman thermography is here assessed for instantaneous measurements in flames, including spray or oxyfuel flames.

\section{Experimental set-up and post-processing}

The laser source consists in a Nd:YAG laser (Agilite Continuum) operating at $10 \mathrm{~Hz}$ providing up to $1.8 \mathrm{~J}$ with tophat pulse with a long pulse duration adjustable from $200 \mathrm{~ns}$ till $1 \mu \mathrm{s}$. The laser beam is focused using a convergent lens with a $1 \mathrm{~m}$ focal-length providing a probe volume of $170 \mu \mathrm{m}$ - thick $\left(1 / \mathrm{e}^{2}\right)$. The SRS light is collected at $90^{\circ}$ with a large solid angle (f/2). The scattered light at the laser wavelength is suppressed by a notch filter (NF03-532E, Semrock). Then, a periscope is used to rotate the image of the laser beam parallel to the entrance slit of the spectrograph (IsoPlane SCT 320, Princeton Instruments) equipped with a grating of 600 grooves $/ \mathrm{mm}$ and providing a spectral resolution of $0.67 \mathrm{~nm}$. The detector camera was a full-frame back-illuminated CCD (Pixis 400B, Princeton 
Instruments). The line-wise measurements were performed by imaging almost $3 \mathrm{~mm}$ of laser beam, divided in 8 local probe volumes of 50 pixels selected by hardware binning, leading to a spatial resolution of $330 \mu \mathrm{m}$.

The collection was gated by a fast electro-optical shutter composed of a Pockels Cell Shutter (PCS) [10] to limit flame emission background. With the PCS switched on, the flame emission was integrated during a small time interval (500 ns or $1 \mu \mathrm{s})$ chosen to fit the laser pulse duration.

Temperature was determined by the procedure proposed by Lo et al [9] where the theoretical spectra were convoluted with the in-situ apparatus function and automatically least-square fitted to the experimental spectra.

\section{Results}

Bunsen burner flames are investigated fed with methane-air mixtures, ethanol vapor-air loaded with ethanol droplets, or $\mathrm{CH}_{4}-\mathrm{CO}_{2}-\mathrm{O}_{2}$ mixtures. Photograph in Fig. 1 shows the intense Mie scattering of droplets, making impossible temperature measurement by Rayleigh scattering in such a configuration. Figure 1-right illustrates the good signal-to-noise ratio of $\mathrm{N}_{2}$ instantaneous spectra, allowing a theoretical spectrum to be correctly adjusted and the temperature to be determined. In gas flames, the method proposed provides accurate temperature measurements of gas flame with an accuracy of $25 \mathrm{~K}$ at $2100 \mathrm{~K}$, and statistical uncertainties around $3 \%$ for single-shot measurements with a SNR of 30 for the $\mathrm{N}_{2}$ peak, which is the parameter affecting in first order the uncertainty.
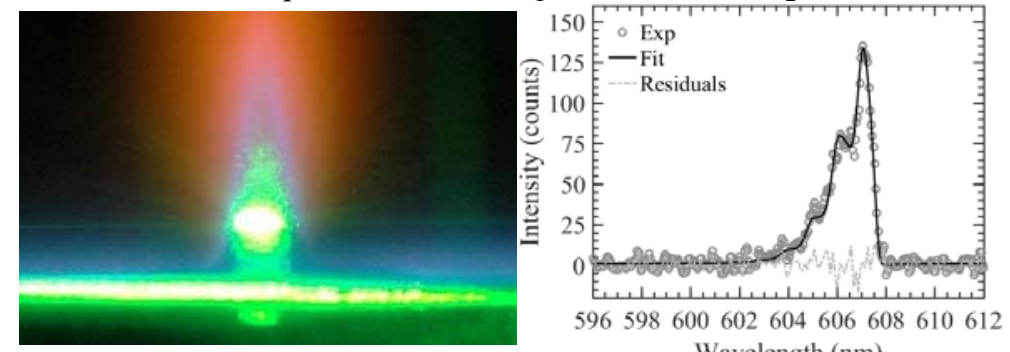

Figure 1

Line-wise measurements require a high accuracy along the complete probe volume, while the apparatus function can be affected by the location considering the short focal length of the collection lens and the moderate length of the spectrograph. The procedure to determine the apparatus function at each probe volume leads to a high accuracy of the temperature measurement along the complete length probed (maximum error of $1 \%$ in burnt gas) and provides accurate measurements with temperature as low as $500 \mathrm{~K}$, while with low dispersion spectra used for multispecies measurements the minimum temperature is $800 \mathrm{~K}$ when Stokes/Antistokes band ratio is used.

In two-phase flames, the accuracy and precision are identical as in gas flames for a same signal level, despite the strong elastic scattering. However the laser energy was a little reduced to avoid optical breakdown, leading to precision of $4.6 \%$ in burnt gas. The method is extended to oxyfuel flames, where $\mathrm{N}_{2}$ is absent.

This work is funded by the BIOENGINE project co-financed by the European Union (ERDF) and the Normandie Regional Council.

\section{References}

[1] R.S. Barlow, Laser diagnostics and their interplay with computations to understand turbulent combustion, Proc. Comb. Inst. 31 (2007) 49-75. [2] F. Fuest, R.S. Barlow, J.-Y. Chen, A. Dreizler, Raman/Rayleigh scattering and CO-LIF measurements in laminar and turbulent jet flames of dimethyl ether, Combust. Flame 159 (2012) 2533-2562.

[3] M. Lapp, L.M. Goldman, C.M. Penney, Raman Scattering From Flames, Science 175 (1972) 1112-\&.

[4] N.M. Laurendeau, Temperature-Measurements By Light-Scattering Methods, Progress in Energy and Combustion Science 14 (1988) 147170 .

[5] G. Grünefeld, V. Beushausen, P. Andresen, W. Hentschel, Spatially resolved Raman scattering for multi-species and temperature analysis in technically applied combustion systems: Spray flame and four-cylinder in-line engine, Applied Physics B 58 (1994) $333-342$.

[6] A.R. Masri, Dibble, R.W., Barlow, R.S.,, Raman-Rayleigh Scattering Measurements in Reacting and Non-Reacting Dilute Two-Phase Flows, J. Raman Spectrosc. 24 (1993) 89-

[7] A. Lo, G. Cléon, P. Vervisch, A. Cessou, Spontaneous Raman scattering: a useful tool for investigating the afterglow of nanosecond scale discharges in air, Applied Physics B: Lasers and Optics 107 (2012) 229-242.

[8] A. Lo, A. Cessou, P. Boubert, P. Vervisch, Space and time analysis of the nanosecond scale discharges in atmospheric pressure air: I. Gas temperature and vibrational distribution function of N 2 and O 2, J. Phys. D: Appl. Phys. 47 (2014) 115201.

[9] A. Lo, F. Frat, E. Domingues, A. Lacour, B. Lecordier, P. Vervisch, A. Cessou, Nanosecond pulsed discharge in a propane-air mixture: Ignition and energy deposition, Proc. Comb. Inst. 36 (2017) 4087-4094.

[10] H. Ajrouche, A. Lo, P. Vervisch, A. Cessou, Assessment of a fast electro-optical shutter for 1D spontaneous Raman scattering in flames, Measurement Science and Technology 26 (2015) 075501. 